\title{
T2-mapping and T2*-mapping for detection of intramyocardial haemorrhage: a head-to-head comparison with $\mathrm{T} 2$-weighted imaging
}

\author{
Pankaj Garg ${ }^{*}$, Ananth Kidambi, David P Ripley, Adam K McDiarmid, Peter P Swoboda, Tarique A Musa, \\ Bara Erhayiem, Laura E Dobson, John P Greenwood, Sven Plein
}

From 18th Annual SCMR Scientific Sessions

Nice, France. 4-7 February 2015

\section{Background}

A variety of CMR methods for detecting intramyocardial haemorrhage (IMH) has been proposed, including T2weighted imaging (T2w), T2-mapping and $\mathrm{T} 2 *$ mapping. IMH detected by $\mathrm{T} 2 \mathrm{w}$ imaging is associated with adverse LV remodelling and adverse outcome post acute myocardial infarction (MI). We compare the sensitivity, specificity, CNR and SNR of the three IMH imaging techniques.

\section{Methods}

Twenty patients underwent CMR at 3T (Achieva TX system, Philips Healthcare, Best, The Netherlands) within 3 days following reperfused ST-elevation MI. Black blood, cine, T2w, T2-mapping, T2*-mapping and LGE imaging $(0.1 \mathrm{mmol} / \mathrm{kg}$ gadolinium DTPA) were performed in identical short axis locations using the ' 3 of 5 ' approach. Data were evaluated offline using commercial software (cvi42 v4.1.5, Circle Cardiovascular Imaging Inc., Calgary, Canada). On the LGE images showing the largest infarct volume, infarct size was determined by using a semi-automated histogram-based thresholding method. This slice was evaluated for visual presence of IMH by the three methods. Signal intensity (SI) and respective standard deviation of SI (SD) were measured for the infarcted myocardium, remote myocardium and any IMH (if present). SNR was computed for each using the formula $=0.655((\mathrm{SI}) /(\mathrm{SD}))$. CNR was determined comparing contrast-to-noise of infarcted myocardium to $\mathrm{IMH}\left(\mathrm{SNR}_{\mathrm{i}}-\mathrm{SNR}_{\mathrm{IMH}}\right)$.

\section{Results}

Of the twenty patients, $55 \%(\mathrm{n}=11)$ had IMH on T2wimaging. The mean ( \pm standard deviation) SNR and CNR values are listed in Table 1 . The visual assessment of $\mathrm{T} 2 \mathrm{w}$ imaging correlated strongly to $\mathrm{T} 2$-maps $(\mathrm{r}=0.69$; $\mathrm{p}=0.001)$ and to the $\mathrm{T} 2{ }^{*}$-maps $(\mathrm{r}=0.60 ; \mathrm{p}=0.005)$. The SNR for IMH and infarct zone were significantly different for only T2w imaging (Figure 1). Quantitative CNR for $\mathrm{T} 2 \mathrm{w}$ imaging correlated strongly to visual assessment of all three imaging modalities (T2 $\mathrm{w}-\mathrm{r}=0.650 ; \mathrm{p}=0.002$, T2-map- $\mathrm{r}=0.454 ; \mathrm{p}=0.04$, T2 ${ }^{*}$-map- $\mathrm{r}=0.603 ; \mathrm{p}=0.005$ ). The CNR for T2-maps and T2*-maps did not show similar correlation to the visual assessment.

\section{Conclusions}

Quantitative and qualitative T2w-imaging assessment for IMH is superior to T2-mapping and T2*mapping.

\section{Funding}

JPG and SP receive a research grant from Philips Healthcare. SP is funded by British Heart Foundation fellowship (FS/10/62/28409).

Table 1 Mean \pm standard deviation (SD) of SNR and CNR values for the three imaging modalities.

\begin{tabular}{cccc}
\hline & T2-weighted & T2-maps & T2*-maps \\
\hline SNR IMH & $3.99 \pm 1.49$ & $4.16 \pm 1.69$ & $9.62 \pm 7.16$ \\
\hline SNR Infarct & $5.45 \pm 2.35$ & $5.30 \pm 3.55$ & $15.45 \pm 28.40$ \\
\hline SNR Remote Myocardium & $4.53 \pm 1.66$ & $11.18 \pm 11.01$ & $10.94 \pm 11.86$ \\
\hline CNR & $0.938 \pm 1.34$ & $0.22 \pm 1.90$ & $6.79 \pm 25.57$ \\
\hline
\end{tabular}



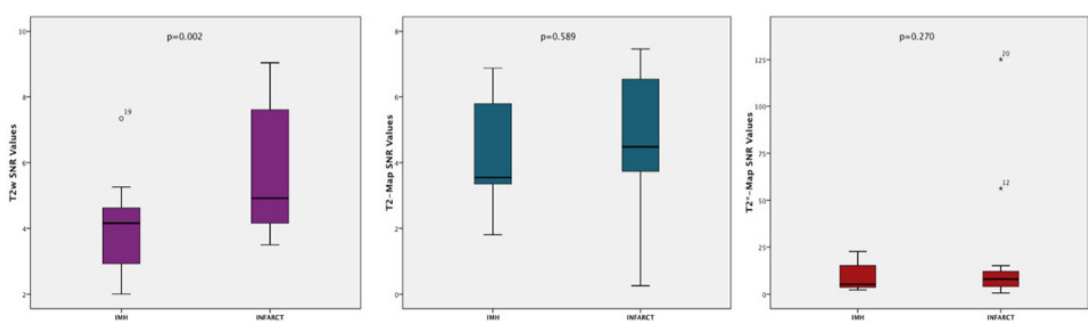

Figure 1 Box-plot of mean \pm standard deviation (SD) of Signal-to-Noise-Ratio (SNR) for IMH and Infarct using the three imaging techniques.

Published: 3 February 2015

doi:10.1186/1532-429X-17-S1-P80

Cite this article as: Garg et al:: T2-mapping and T2*-mapping for

detection of intramyocardial haemorrhage: a head-to-head comparison

with T2-weighted imaging. Journal of Cardiovascular Magnetic Resonance

2015 17(Suppl 1):P80.

Submit your next manuscript to BioMed Central and take full advantage of:

- Convenient online submission

- Thorough peer review

- No space constraints or color figure charges

- Immediate publication on acceptance

- Inclusion in PubMed, CAS, Scopus and Google Scholar

- Research which is freely available for redistribution

Submit your manuscript at www.biomedcentral.com/submit 